\title{
Partidos políticos e política externa durante a administração Lula
}

\author{
Political parties and foreign policy during Lula's administration
}

\author{
Matheus Lucas Hebling \\ Graduado em Ciências Sociais com ênfase em \\ Ciência Política, Bolsista do Conselho Nacional de \\ Desenvolvimento Científico e Tecnológico (CNPq), \\ Mestrando pelo Programa de Pós-Graduação em \\ Ciência Política, Universidade Federal de São Carlos \\ (UFSCar), São Carlos, SP, Brasil \\ matheushebling@gmail.com
}

\begin{abstract}
Resumo: Os partidos políticos têm papel fundamental na representação de interesses e desempenham talvez a mais forte ligação entre o governo e os cidadãos. Dentro dos estudos de política externa, esses possuem um papel secundário na sua produção. Entretanto, parte-se do pressuposto, neste trabalho, que o Chefe do Executivo está diretamente ligado ideologicamente a seu partido e que um não pode ser desligado do outro para tal análise. O objetivo desse trabalho é mapear e avaliar a agenda política legislativa do Presidente Luiz Inácio Lula da Silva (2003 - 2010), através da análise das leis ordinárias enviadas por ele para deliberação do Congresso Nacional, procurando entender quais as características da sua formação no Congresso em matérias de política externa. Verifica-se um destaque dos organismos internacionais e da multilateralidade, assim como a centralidade da defesa nacional no Poder Executivo.
\end{abstract}

Palavras-chave: Poder executivo; Agenda building; Política externa.

Abstract: Political parties play a key role in interest representation and perhaps play a stronger connection between the government and citizens. Within the foreign policy studies, these have a secondary role in its production. However, it is assumed in this work that the Chief Executive is directly linked ideologically to his party and cannot be disconnected from each other to such an analysis. The aim of this study is to map and assess the legislative agenda of President Luiz Inácio Lula da Silva (2003 - 2010), by analyzing the ordinary laws sent by him for resolution to the National Congress, trying to understand what are the features of its formation in Congress in foreign policy matters. There is a highlight of the international organizations and multilateralism, as well as the centrality of national defense in the Executive branch.

Keywords: Executive branch; Agenda building; Foreign policy. 


\section{Introdução}

O presente trabalho tem como objetivo avaliar quais são as características da agenda legislativa do Presidente Luiz Inácio Lula da Silva (2003-2010) em matérias de política externa, através da análise empírica de todas as propostas de legislação ${ }^{1}$ submetidas ao Congresso. Algumas considerações teórico-metodológicas são necessárias de serem feitas: primeiro, parte-se do pressuposto política externa é entendida como uma forma de política pública (DINIZ; RIBEIRO, 2008; LENTNER, 2006; LIMA, 2000; MILANI; PINHEIRO, 2013); segundo, que as agendas presidenciais são passíveis de serem medidas e suas características, identificadas e comparadas (BAUMGARTNER; JONES, 1993) ${ }^{2}$. Dessa maneira, pode-se calcular quantas propostas foram enviadas ao Poder Legislativo; entender qual a composição das políticas públicas; e quão original ou ambiciosa essas propostas são. Assim, transforma-se a agenda presidencial em política externa em variáveis que podem ser medidas. Terceiro, seguindo o modelo proposto por Hermann e Hermann (1989), teoriza-se que a política externa esteja inserida em um grupo de múltiplos atores, entendidos como indivíduos, grupos (como partidos políticos) ou coalizões que devem chegar a acordos para atuarem no governo, no qual o chefe de governo é tido como um de vários atores presentes no processo de barganha que eventualmente resulta em uma decisão. O Chefe do Executivo está, portanto, preso a negociações domésticas dentro do seu partido e inserido em uma trama político-ideológica que deve ser respeitada.

A análise será feita usando o esquema de codificação proposto por Katznelson e Lapinski (2006), que permite que tenhamos uma caracterização mais acurada da política pública através do tempo e que abre portas para a comparação de legislaturas e representação, iniciada por Lowi (1964; 1970). A codificação, inicialmente criada para o estudo de políticas públicas doméstica e externa nos Estados Unidos, pretende preterir a política "macro" e parte para o estudo do conteúdo daquilo que é feito em uma democracia liberal, dado que a política está ligada a diferentes arenas, seja ela a política nacional, econômica, social ou internacional. O ponto de vista tanto desses autores quanto o deste trabalho, é que representação e política pública andam lado a lado uma da outra, e estão submetidas a pressões similares, como composição do governo,

\footnotetext{
Foi necessário fazer um recorte de pesquisa, e a análise focalizou-se nas leis ordinárias submetidas pela Presidente ao Congresso no período informado (BRASIL, 2015a). Toda a base de dados está disponível online através do site www4.planalto.gov.br/legislação

2 De acordo com Kingdon (2003), uma confluência de fluxos (problemas, soluções e alternativas) é necessária para que o governo participe da resolução de um problema.
}

polarização, ideologização, impacto da opinião pública, produtividade legislativa, importância de comitês e partidos e, não menos importante, a conexão eleitoral. Após a codificação de cada uma das propostas, as mesmas serão analisadas qualitativamente, com o objetivo de entender quais as características da agenda presidencial no Congresso. Tal análise, denominada análise documental possibilita a articulação entre a problemática proposta pelo pesquisador e informações advindas da documentação sob avaliação, em uma tentativa de elaborar explicações coerentes (CELLARD, 2008).

O artigo está organizado em três partes: primeiro, será feito um levantamento de qual a relação entre partidos políticos e a representação de interesses; em uma segunda parte, tentar-se-á responder a questão de como os partidos políticos podem influenciar na política externa e como esta consegue influenciar o ambiente doméstico e, em um terceiro momento, a tentativa será de compreender quais foram as características da agenda presidencial-partidária das administrações petistas no Congresso em Política Externa, sob o comando de Luiz Inácio Lula da Silva.

\section{Partidos políticos e representação de interesses}

Huntington apud Eldersveld (1982) define alguns estágios pelos quais os partidos passam nas sociedades modernas, iniciando por um período de facciosismo/partidarismo; passando por uma polarização de forças sociais, que leva à emergência de estruturas partidárias iniciais; por uma terceira fase de expansão do eleitorado e do aperfeiçoamento da organização partidária; e, por fim, pela fase da institucionalização, do estabelecimento de partidos que são coerentes e que possuem estruturas complexas que são adaptáveis e viáveis. Embora não seja uma lei, é interessante pensar a partir desse esquema no nascimento dos partidos políticos a partir de diferentes opiniões sobre aquilo que a sociedade deveria se tornar. Um exemplo claro são os Estados Unidos, cuja cultura partidária surge a partir do momento em que diferentes normas e credos $^{3}$ sobre como o sistema partidário deveria funcionar começaram a emergir, fruto da experiência e transmissão entre cidadãos (ELDERSVELD, 1982).

Duverger (1970), um dos primeiros estudiosos sobre partidos políticos, aponta que os partidos políticos nascem a partir de elementos comuns que os unem, como

\footnotetext{
3 A relação entre diferentes clivagens sociais e a função dos partidos políticos é melhor delineada em Lipset e Rokkan (1967), cuja explicação baseia-se na importância histórica na análise de um partido político e na relevância dos momentos críticos que produzem clivagens sociais, que por sua vez, se reproduzem nos partidos.
} 
ideologia, geografia, interesses comuns ou mesmo fatores locais. Para o autor, conforme a sua origem, existirão elementos que influenciarão a estrutura posterior dos partidos, seja ela parlamentar/eleitoral ou externa. Logo, partidos burgueses, socialistas, comunistas, fascistas, entre outros, possuíam diferentes características, que eram reflexo da marca de seu nascimento.

De acordo com Eldersveld (1982), teórico do desenvolvimento político, dentro da sociedade contemporânea muitas são as ligações existentes entre o governo e o povo, representadas em estruturas organizativas intermediárias que promovem ações positivas e decisões efetivas em face à fragmentação, conflito e envolvimento de massa. É o partido político que representa (se não a maior) uma das maiores ligações, uma vez que permite a interação e coesão entre legisladores, o Poder Executivo e a relação entre eles; baseia a cooperação entre instituições nacionais, internacionais e locais; uma arena na qual diferentes interesses podem ser ouvidos e canalizados em uma estrutura de poder, que cria coalizões para objetivos específicos e, por fim, um canal para ligar cidadãos, funcionários do governo e líderes organizacionais. Os partidos são, portanto, grupos que mediam, articulam e resolvem conflitos, podendo ser ideológicos, personalistas ou pragmáticos. Essa mesma ideia é compartilhada por Lipset (1993, p. 47):

Political parties themselves should be viewed as mediating institutions between the citizenry and the state. A crucial condition for a stable democracy is the presence of major parties with large and virtually permanent bases of support among voters.

Eldersveld (1982) aponta a ligação governo $\leftrightarrow$ público, representada na Figura 1 abaixo e cercada de organizações intermediárias.

Para Aldrich (1985), pai da literatura da escolha racional aplicada aos partidos políticos, um partido político é uma instituição endógena moldada por atores políticos (para candidatos e funcionários públicos) e é o principal instrumento que ajuda os políticos atingirem seus objetivos (uma carreira longa e bem sucedida em cargos políticos, a realização de fins políticos e poder e prestígio dentro do governo). Essa forma de ajuda depende de três variáveis: a organização política (eleitorado), a definição institucional (a forma de governo) e o contexto histórico (ideias, valores, condições tecnológicas e também seu desenvolvimento - path dependency). As duas primeiras variáveis criam ação coletiva e problemas de escolha coletiva e o contexto histórico determina se as partes são o meio mais eficiente de resolver esses dois problemas.

Os partidos, logo, são agregadores de interesse e buscam apelar à maioria do público e devem possuir

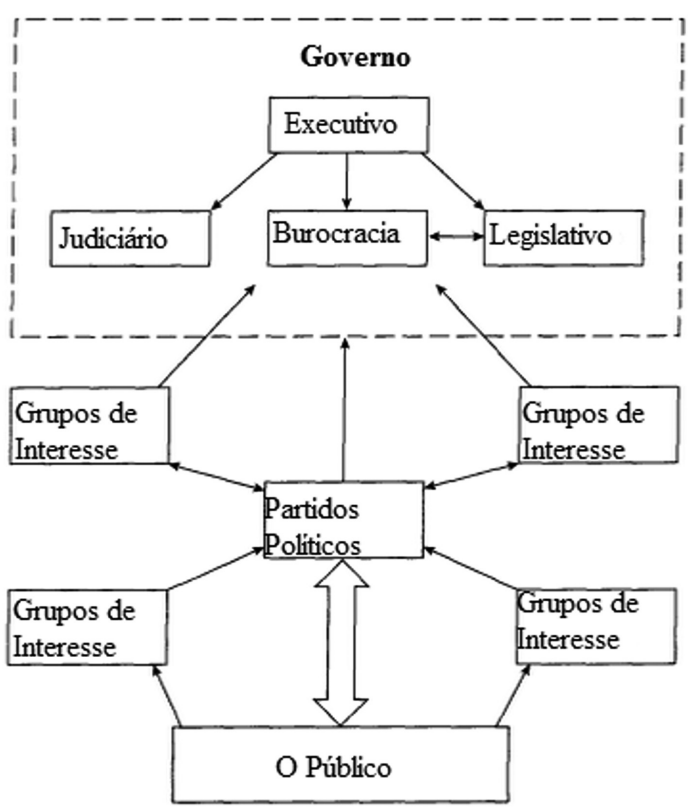

Figura 1. Partidos como Estruturas de Ligação. Fonte: Eldersveld (1982, p. 2).

quatro características para serem entendidos como um bom partido: assumir compromissos políticos para com o eleitorado; realizá-los no governo; quando fora do governo, possuir alternativas às políticas atuais; ser suficientemente diferentes para oferecerem aos eleitores uma escolha real. Por consequência, Aldrich concorda com Eldersveld ao defender que o papel dos partidos seja justamente lidar e resolver problemas que os desenhos institucionais atuais não conseguem e que políticos acreditam que não conseguem sozinhos.

Entretanto, é importante notar que se os partidos nascem do dissenso, não é possível que exista apenas um tipo de partido. Vários foram os autores que estudaram e caracterizaram os partidos políticos em diferentes locais e tempos. Mair (1997) identifica alguns deles, a saber: o partido de elite, o partido de massas, o partido catch-all e o partido cartel. Faremos uma breve discussão sobre cada um deles.

Característico do século XIX, o partido de elite era altamente restrito no que tangia a distribuição de recursos políticos e sua filiação era igualmente pequena e elitizada, baseada em redes de comunicação intrapessoais e assentado sob uma fronteira obscura entre o Estado e a sociedade civil, cuja figura do trustee era o seu estilo de representação.

Inicialmente teorizado por Duverger (1954), o partido de massa era comum entre o século XIX até a metade do século XX, e estava inserido em um contexto em que a política era essencialmente competição, conflito, cooperação de grupos políticos, 
os quais participam da política justamente através dos partidos, que fornecem uma ligação entre cidadãos e o Estado, mesmo tendo seus recursos relativamente concentrados. Aqui, os partidos têm como base de competição a capacidade representativa de seus candidatos e como objetivo principal de suas políticas a reforma social (ou oposição à ela).

Com o aumento do sufrágio, o enfraquecimento de identidades coletivas, o desenvolvimento econômico e da mídia de massa nos anos 1950 e 1960, surgiu um novo tipo de partido, denominado originalmente por Kirchheimer (1966) de partido catch-all, cujo objetivo principal era a melhora social, através de fundos angariados de diferentes fontes e filiação aberta e encorajada a todos. O partido catch-all perde seu viés ideológico para tentar abarcar mais demandas diferentes, não mais as estabelecendo, mas as selecionando. A figura principal dentro deles é o empreendedor.

Por fim, o partido cartel nasce em um contexto sócio-político em que o sufrágio tornou-se universal, em que a política é tida como profissão e a campanha eleitoral é feita através do uso intensivo de capital financeiro. O partido aqui enfatiza membros individuais e não mais um grupo como um todo e o partido se torna parte do Estado.

Uma última observação precisa ser feita: ao tentar resolver as ambiguidades presentes na teoria de Kirchheimer (1966), Panebianco (2005) traduz a caracterização feita pelo autor em termos organizacionais, tornando a mudança de um partido burocrático de massa (nos termos de Duverger, partido de massa) para um partido profissional-eleitoral. Esse segundo se caracteriza por estar centrado em profissionais, cuja orientação passa a ser eleitoral e os representantes públicos contam com uma maior importância do personalismo. O financiamento do partido é feito através de fundos públicos e privados, por meio de grupos de interesses e as ligações organizativas verticais são cada vez mais frágeis. Tal transformação se dá proporcionalmente mais rápida quanto mais fraco for o grau de institucionalização de cada partido, influenciado pelo ambiente e pelo eleitorado.

\section{Partidos políticos e política externa}

A análise de política externa pode ser feita através de diferentes níveis, como o individual, governamental/estatal ou o internacional. Dentro do contexto deste trabalho, seguiremos o nível governamental/estatal como o principal de análise, dado que o foco presente é no Chefe do Executivo e seu respectivo partido político.

A política externa é feita e conduzida em um complexo ambiente que perpassa os limites domésticos, chegando ao ambiente internacional, normalmente envolvendo diferentes atores na sua formulação, como governos, empresas, grupos de interesse, em um jogo político que envolve barganha e compromisso. Nesse cenário, a abertura de mercados, a globalização e o avanço das comunicações operam erodindo a soberania nacional e permitindo que fronteiras domésticas e internacionais se tornem toldadas. De acordo com Putnam (1988), a relação entre o sistema internacional e o nível governamental se relacionarão em jogos políticos de dois níveis, nos quais tanto o interesse interno deve ser maximizado e consequências externas, reduzidas no nível internacional (nível I), como pressões de diferentes grupos de interesse são acossadas no nível doméstico (nível II). Milner (1997) argumenta de maneira similar, ao defender que existe uma ligação direta entre atores domésticos e externos, em um cenário denominado poliárquico, dada a divisão do poder e autoridade no processo decisório entre diferentes atores. Além disso, Rogoswki (1999) enfatiza a importância do desenho institucional e possíveis constrangimentos que possam ocorrer no processo decisório de uma política externa, como o direito ao voto de diferentes grupos domésticos, a representação/modo de seleção dos votantes e as regras decisórias como um todo.

Contudo, qual o papel de um partido político na formulação de política externa? Aldrich et al. (2006) sugere que uma vez que o público possui diferentes atitudes e credos para com uma política, os mesmos refletirão tais atitudes em um contexto eleitoral. Assim, candidatos de diferentes partidos devem oferecer alternativas coerentes e distintas sobre como lidar com a política externa de seu país, especialmente ao vermos que a política econômica pode se tornar central no seu debate, como pela liberalização do comércio entre países. A ligação entre política externa e economia vai além da conexão eleitoral, pois divide características centrais a atores políticos, como a facilidade de se fazer avaliações retrospectivas, resultados facilmente avaliados, grande incerteza em vincular a forma como a política conecta-se aos resultados. Por muitas vezes, tal afinidade se explica pela influência da ideologia partidária sobre interesses econômicos (OLIVEIRA; ONUKI, 2010).

A presença de dois fatores políticos também interfere nas alterações feitas a uma política externa, sendo eles a oposição de um partido político ${ }^{4}$ e a oposição pública ${ }^{5}$, especialmente presentes quando envolvem grandes poderes políticos, política econômica externa e diplomacia. Isto posto, Hagan (1993) destaca os efeitos sobre a política externa da oposição partido

\footnotetext{
${ }^{4} \mathrm{O}$ conflito pode representar um feedback positivo (PIERSON, 2004) ou um mecanismo da reprodução (THELEN, 1999) que perpetua alinhamentos entre partidos e eleitores.

5 Ver Holsti (1992), Risse-Kappen (1991).
} 
Quadro 1. Esquema de codificação política.

\begin{tabular}{lll}
\hline \multicolumn{1}{c}{ Camada 1 } & \multicolumn{1}{c}{ Camada 2 } & \multicolumn{1}{c}{ Camada 3 } \\
\hline $\begin{array}{l}\text { Relações } \\
\text { Internacionais }\end{array}$ & Defesa & $\begin{array}{l}\text { Organização e desenvolvimento da Força Aérea; Organização e } \\
\text { Desenvolvimento do Exército; Recrutamento e Alistamento; Milícias; } \\
\end{array}$ \\
& & $\begin{array}{l}\text { Organização e desenvolvimento Naval; Organização Militar geral; } \\
\text { Instalaçoses militares; Defesa Civil e Pátria }\end{array}$ \\
& Geopolítica & $\begin{array}{l}\text { Diplomacia/Inteligência; Ajuda financeira internacional; Organizações } \\
\text { Internacionais }\end{array}$ \\
& $\begin{array}{ll}\text { Economia Política } \\
\text { Internacional }\end{array}$ & Naval; Comércio/Aduaneira; Organizações Econômicas Internacionais \\
\hline
\end{tabular}

Fonte: Katznelson e Lapinski, (2006, p. 112-113). Tradução do autor.

político como função de dois atributos: (1) a sua força, e (2) a intensidade de oposição. A força da oposição de um partido é baseada em seu número de cadeiras no Legislativo. Assim, a força dos partidos de oposição pode ser analisada na base de comparação entre o número de cadeiras controladas pelo partido do governo (ou partidos presentes na coalizão governista) e o total combinado controlado pela a oposição, podendo também ser observada pela coesão ${ }^{6}$ da oposição. A intensidade, por outro lado, refere-se à rigidez com a qual um (ou mais) partido(s) se opõe ao governo? ${ }^{7}$. Essa oposição de partidos pode funcionar como um portador (incentivador) ou barreira (manutenção do status quo) para a mudança (KLEISTRA; MAYER, 2001).

Para Martin (2000), a influência legislativa (partidos e legisladores) sobre a política internacional do Estado é, ao mesmo tempo, profunda e sutil; e sua participação na política internacional explica o sucesso que Estados democráticos tiveram em ganhar guerras e cooperar, uma vez que o envolvimento das legislaturas aumenta a credibilidade da posição dos Estados, que por sua vez aumenta a confiança entre os mesmos. É somente quando os executivos tentam marginalizar legislaturas que problemas de política externa podem surgir. A autora enfatiza que o Legislativo pode passar autoridade sobre política internacional para o executivo, mantendo o controle final sobre o processo, através das opções de retirar autoridade ou recusar-se a ratificar qualquer resultado que o executivo possa alcançar. $\mathrm{O}$ legislador pode exercer uma influência sutil sobre as ações do poder executivo, por métodos como atraso, obstrução e retenção de fundos. O Executivo vai estar atento a tais táticas e modificar seu comportamento em conformidade.

\footnotetext{
${ }^{6}$ A própria formação dos partidos resulta na existência de um partido coeso ou não. Eldersveld (1982) aponta alguns determinantes na formação de um partido, como os padrões iniciais de conflito, condições em que o sufrágio fora estendido, constituição política e particularidades do sistema eleitoral, assim como socialização cidadã e responsividade partidária aos problemas sociais.

7 Ver também Hagan (1995).
}

\section{Análise empírica}

Metodologicamente, as leis foram agrupadas seguindo as categorias criadas por Katznelson e Lapinski (2006). O objetivo da criação de tais categorias é justamente de possibilitar estudos de representação e política pública de maneira comparada. Aqui, parte-se de dois pressupostos: o primeiro, que a política pública é tomada como variável independente e o segundo, que os legisladores possuem preferências diferentes, tratando as políticas públicas como multidimensionais, polivalentes e passíveis de serem afetadas por diferentes problemas. Dentro do recorte desse artigo, para entender as matérias de política externa do país, foi selecionado o domínio de políticas públicas (policy domain) das "Relações Internacionais". Tal domínio, mais geral, compreende três agrupamentos de políticas públicas (policy clusters), sendo elas "Defesa", "Geopolítica" e "Economia Política Internacional", que por sua vez, possuem áreas mais específicas (policy areas), que seguem no Quadro 1.

Analisar-se-ão as leis ordinárias enviadas pelo Presidente Luiz Inácio Lula da Silva durante os seus dois mandatos. Como o objetivo deste trabalho é entender a formação da Política Externa como um todo, não serão feitas diferenciações entre os dois mandatos. Além disso, o recorte teórico feito aqui coloca o Presidente da República como um representante do seu partido no Poder.

No período coberto pela pesquisa foram encaminhados pela Presidência da República para deliberação no Congresso 89 leis que versam sobre política externa. Entretanto, dentro de cada uma das leis pode existir mais de uma proposta. Por exemplo, na mesma lei o Presidente pode enviar ajuda financeira a mais de um conflito no mundo, tratar de diferentes planos para a organização das forças armadas ou mesmo fomentar diferentes organizações internacionais. Dessa maneira, foram considerados todos os itens separadamente para que a análise empírica fosse mais verossímil possível, totalizando 140 propostas enviadas ao Congresso. 
Como cada uma das propostas foram consideradas separadamente e há a possibilidade de veto total ou parcial por ambas as partes, a análise não fica prejudicada. Há de se notar que foram poucas as vezes que isso ocorreu, e quando aconteceu, foi relacionado às organizações internacionais e ao desenvolvimento das Forças Armadas, como demonstrar-se-á em breve.

De maneira geral, é importante observar que, graças à exclusividade orçamentária do Poder Executivo, grande parte das leis enviadas ao Congresso são relativas à aprovação de recursos financeiros aos diferentes Ministérios que apareceram durante a análise, como o Ministério da Defesa, das Relações Exteriores e do Desenvolvimento, Indústria e Comércio Exterior.

Os dados apontam para um balanço entre as proposições enviadas que tangem as categorias de Defesa e Geopolítica, com 89 proposições para a primeira e 88 para a segunda, enquanto a categoria de Economia Política Internacional teve 23 leis enviadas ao Congresso pelo Poder Executivo. O Gráfico 1 resume os dados, separados por área (policy cluster).

A preponderância da área de Defesa pode ser explicada, dentro da corrente teórica do Realismo nas Relações Internacionais justamente por ser o núcleo de interesse do Estado. Para ela, a anarquia, o poder e seu equilíbrio e o interesse nacional são conceitos centrais para se entender a inserção de um Estado no sistema internacional. A motivação de atores, portanto, perpassa a segurança e a manutenção e crescimento do poder, em uma perspectiva pessimista do quadro internacional (JACKSON; SØRENSEN, 2007). Já a preponderância da geopolítica se explica pela extensão territorial, poder econômico crescente e militar do país, que permite ao Brasil atuar independentemente no cenário internacional e também influir nos outros Estados, podendo se expressar como uma potência regional dado que, segundo Deutsch (1967), a importância do status de poder pode ser vista como uma estimativa dos recursos materiais e humanos usados para prever quanto êxito um país pode ter. Assim, quanto mais extenso, mais populoso e mais recursos mobilizar, maiores serão as possibilidades políticas do país.

Para se ter uma melhor compreensão de quais são os temas, áreas e características centrais da agenda de política externa feita durante o governo Lula (2003-2010), far-se-á uma separação nos diferentes policy clusters, na seguinte ordem: Defesa, Geopolítica e Economia Política Internacional.

Das 89 leis ordinárias enviadas ao Congresso pelo Presidente, a maior parte das mesmas se referem à Organização e desenvolvimento das Forças Armadas como um todo (Força Aérea, Exército e Marinha). Essas leis se referem, em geral, à manutenção dos

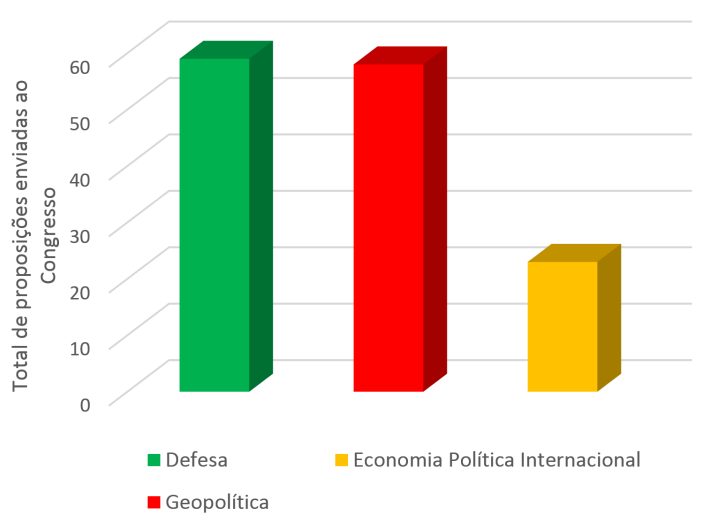

Gráfico 1. Total de Proposições enviadas ao Congresso por área.

militares brasileiros e versam sobre armamento, aquisição de aeronaves munições, fardamento, emprego de força, etc. Tal esforço reflete uma tentativa de modernizar e valorizar as Forças Armadas brasileiras. Um exemplo é a lei 11.537/2007, que versa sobre a reestruturação da indústria de material bélico no Brasil (BRASIL, 2007). Não houve nenhuma lei que abordou a categoria "milícias" em nenhum dos dois mandados do Presidente.

Dentro do escopo de Defesa, o governo Lula contemplou o desenvolvimento de sítios operacionais com fins de criar um sistema de vigilância na Amazônia, assim como o desenvolvimento de um software de segurança para a patrulha e observação da área, como presente nas leis 11.007/2004 e 11.199/2005 (BRASIL, 2004a, 2005a). Tal projeto, para Almeida (2002), significa trazer benefícios dos mais variados tipos, como econômicos, políticos e sociais, pois enseja a possibilidade da presença governamental em uma área que antes não contava com a mesma. Como propõem Pieranti e Silva (2007a, p. 8):

[...] as políticas de defesa nacional e de meio ambiente esbarram na dificuldade que os atores ligados ao Estado têm de acesso à área a ser fiscalizada. As grandes distâncias, a precária infraestrutura e as restrições territoriais - particularmente, quanto às reservas indígenas - tornam-se, ao mesmo tempo, obstáculos a serem ultrapassados pelo Estado e brechas facilitadoras para a ação de agentes externos e grupos criminosos, principalmente, em ações que envolvem o narcotráfico, o tráfico de armas e a exploração ilícita de recursos minerais e vegetais.

Em um esforço de mapear o território marítimo brasileiro, a lei 11.824/2008 (BRASIL, 2008a) dá créditos ao Ministério da Defesa para fazer um levantamento dos limites da plataforma continental brasileira, enquanto a lei 11.814/2008 (BRASIL, 2008b) 
adequa a tecnologia existente do Sistema de Controle do Espaço Aéreo Brasileiro (SISCEAB). As leis 11.224/2005, 12.009/2009, 12.373/2010 (BRASIL, 2005b, 2009a, 2010a) versam sobre a aquisição de aeronaves, cargueiros e helicópteros de médio porte, estampando a preocupação do governo em adequar sua capacidade de defesa frente aos possíveis problemas futuros. No texto da lei 11.957/2009 (BRASIL, 2009b,), o governo justifica a compra reiterando ansiar

Fortalecer a inserção soberana internacional e a integração sul-americana", "Promover a capacitação tecnológica da Aeronáutica e da indústria aeroespacial brasileira" e "Reaparelhar e adequar a Força Aérea Brasileira com a finalidade de recuperar e manter a sua capacidade operacional e proporcionar os meios de apoio necessários ao cumprimento de sua destinação constitucional: "defender a Pátria, garantir os poderes constitucionais e, por iniciativa de qualquer destes, da lei e da ordem.

Ainda na lei 12.373/2010 (BRASIL, 2010a) o governo fomenta a pesquisa para o desenvolvimento tecnológico do ciclo do combustível nuclear para a construção de um protótipo de reator nuclear. O resumo dos dados sobre Defesa segue no Gráfico 2.

Uma menor parte, porém não menos importante das leis enviadas pelo Presidente ao Congresso são referentes à Economia Política Internacional. Primeiro, dentre as 23 proposições de Economia Política Internacional que foram enviadas ao Congresso, foi necessário criar duas categorias extras ao esquema de Katznelson e Lapinski (2006), denominadas "negociações bilaterais" e "fomento ao turismo". Em estudo anterior feito sobre o governo Dilma, Hebling (2014) verificou que, de acordo com a lei $\mathrm{n}^{\circ} 12.915$ de 18 de Dezembro de 2013, (BRASIL, 2013) parte do orçamento da

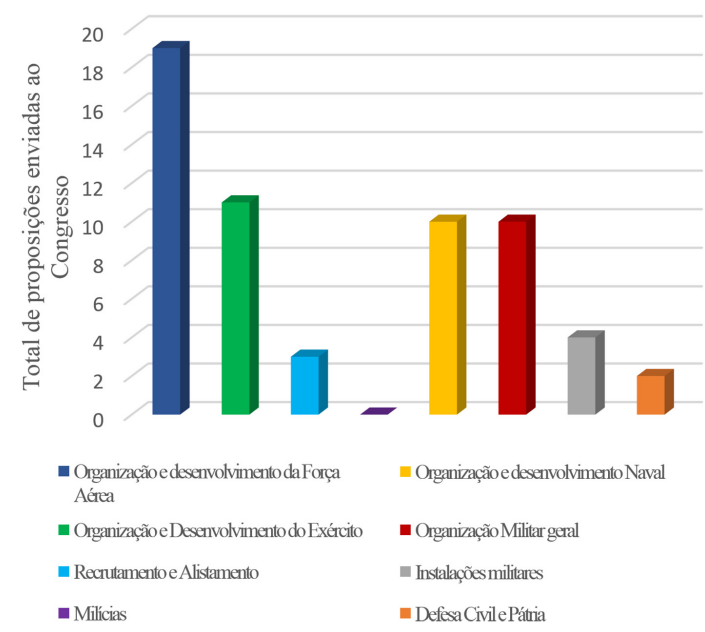

Gráfico 2. Proposições de Defesa enviadas ao Congresso.
União foi para o Ministério das Relações Exteriores, na atividade "Relações e Negociações Bilaterais", em um investimento de $\mathrm{R} \$ 58.840 .996,00$. Não há, no documento, nada que possa determinar mais precisamente onde tal proposta possa ser encaixada. Entretanto, nenhuma proposta no governo Lula se encaixou nessa categoria. A segunda criada, "fomento ao turismo", refere-se às leis 10.818/2003, 11.085/2004 e 11.253/2005 (BRASIL, 2003a, 2004b, 2005c) que dispõem sobre ações de fomento à imagem turística do Brasil no exterior e de fomento à comercialização e ao fortalecimento dos produtos brasileiros juntos aos operadores internacionais.

Ademais, destaque-se a categoria de "comércio/aduaneira" com 17 proposições enviadas ao Congresso, que versam sobre os mais diversos assuntos relacionados ao tópico. As leis 11.081/2004 e 11.225/2005 (BRASIL, 2004c, 2005d) mostram um esforço do governo em modernizar o Sistema Integrado para o Comércio Exterior - SISCOMEX, enquanto a lei 11.071/2004 (BRASIL, 2004d) tem como objetivo "Reduzir o custo do transporte de cargas entre o Brasil e os países do Mercosul". A lei 11.066/2004, por sua vez, pretende

Expandir a pauta brasileira de exportação em quantidade, qualidade e variedade de produtos, mercados de destino e de empresas brasileiras participantes no mercado internacional (BRASIL, 2004e).

Uma forte tendência de apoio ao comércio exterior também é presente na lei 11.852/2008, que promove o marketing e apoio à comercialização nos mercados norte-americano, latino-americano, europeu e "outros mercados" (BRASIL, 2008c).

As proposições relativas à categoria "naval" se expressam em uma tentativa do país renovar sua marinha mercante (BRASIL, 2004f), modernizar e ampliar a estrutura portuária (BRASIL, 2004g, 2005e), assim como fomentar a participação da União na Empresa Brasileira de Infraestrutura Aeroportuária, também presente nas leis 11.206/2005 e 11.517/2007 (BRASIL, 2005e, 2007b).

Dentro da teoria liberalista das Relações Internacionais (CARR, 1945; HOWARD, 1978; MITRANY, 1948; KEOHANE; NYE, 1977), a importância do comércio se justifica a partir do ideal de que o espírito da guerra e do comércio seriam incompatíveis, sendo o comércio livre um meio mais pacífico de alcançar riqueza nacional, podendo igualmente quebrar divisões entre Estados e unir indivíduos de todo o mundo em uma comunidade, ao aumentar o contato e níveis de entendimento entre os povos, encorajando entendimento e amizade internacionais. A remoção de barreiras e o fomento do comércio é, também, o coração da teoria 
moderna da interdependência. Com o aumento da integração econômica, o conflito entre países seria reduzido ao criar um interesse comum, que seria o comércio e a colaboração econômica, que começaria em áreas técnicas e depois passaria às áreas em que vantagens poderiam ser ganhas por ambos os países em negócios.

Fundamental nesse pensamento liberal-institucionalista (YOUNG, 1982; NYE, 1988; POWELL, 1994) é a existência de organizações econômicas internacionais, que podem coordenar a cooperação de Estados através de instituições, ou seja, regras que governam o comportamento estatal em áreas específicas. Durante o governo Lula, apenas uma proposição foi enviada ao Congresso no que concerne as "Organizações Econômicas Internacionais", a lei 11.230/2005, que prevê a contribuição do país à Organização Mundial do Comércio - OMC (BRASIL, 2005f).

O Gráfico 3 resume os dados apresentados acima.

Por fim, o policy cluster de Geopolítica soma 88 proposições que foram enviadas ao Congresso para apreciação. É importante notar que as categorias analíticas propostas originalmente pelo esquema de codificação feito por Katznelson e Lapinski (2006) não foram suficientes para fazer a codificação no governo Lula. Portanto, durante a análise empírica foram criadas duas novas: "ajuda militar internacional" e "fomento educacional" que se distinguem de "ajuda financeira internacional", pois envolvem doações, no caso da primeira, e criação de universidades, no caso da segunda.

Dentro da categoria de "ajuda militar internacional", o Presidente enviou 5 leis ordinárias para apreciação no Congresso. A primeira, de número 10.685/2003 (BRASIL, 2003b), autoriza o Ministério da Defesa a efetuar a doação de uma corveta para a República

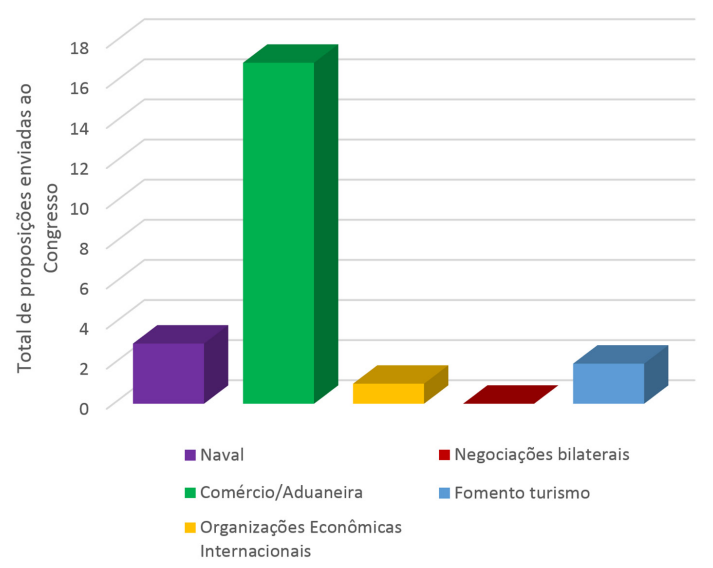

Gráfico 3. Proposições de Economia Política Internacional enviadas ao Congresso. da Namíbia, a lei 12.271/2010 (BRASIL, 2010b) autoriza o Poder Executivo a doar três aeronaves à República do Paraguai. Além disso, é importante destacar a contínua participação militar brasileira no Haiti, após o terremoto e no Timor Leste, dentro da Missão das Nações Unidas, regulamentada pelo texto das leis 10.938/2004, 11.130/2005, 11.537/2007 e $12.257 / 2010$, que versam sobre auxílio financeiro às tropas e a dependentes (BRASIL, 2004h, 2005g, 2007c, 2010c). Na categoria "fomento educacional", as leis 12.189/2010 e 12.289/2010 (BRASIL, 2010d, e) dispõem sobre a criação da Universidade da Integração Internacional da Lusofonia Afro-brasileira-UNILAB, presente nos estados da Bahia e do Ceará, cujo objetivo é integrar os países de língua portuguesa e promover o desenvolvimento científico-cultural dos mesmos:

[...] formar recursos humanos para contribuir com a integração entre o Brasil e os demais países membros da Comunidade dos Países de Língua Portuguesa (CPLP), especialmente os países africanos, bem como promover o desenvolvimento regional e o intercâmbio cultural, científico e educacional. Vocacionada, portanto, para a cooperação internacional e compromissada com a interculturalidade, a cidadania e a democracia nas sociedades, a Unilab fundamenta suas ações no intercâmbio acadêmico e solidário com Angola, Cabo Verde, Guiné-Bissau, Moçambique, Portugal, São Tomé e Príncipe e Timor-Leste. (UNILAB, 2015).

Dentre as 11 leis que versam sobre "Diplomacia/Inteligência", destacam-se duas sobre aquisição de imóveis para a instalação da Embaixada do Brasil. A lei 12.163/2009 (BRASIL, 2009c) prevê a aquisição de imóvel para a chancelaria brasileira em Londres, na Inglaterra. Dessa maneira, externa-se mais uma vez uma aproximação do país junto ao continente africano. Além disso, o Presidente enviou leis que previam alterações na divisão por níveis da carreira de diplomata e extingue os cargos de assistente de chancelaria (BRASIL, 2010f).

A categoria de "ajuda financeira internacional" contou com 16 proposições enviadas ao Congresso para apreciação parlamentar, sendo a segunda mais numerosa dentre a temática de "Geopolítica". Três leis versam sobre a Palestina, sendo a primeira delas 11.953/2009 (BRASIL, 2009d), que abre orçamento para a reconstrução da área Palestina de Gaza, a segunda, 12.231/2010 (BRASIL, 2010g), que discorre sobre a doação de área para a instalação especial Palestina e a terceira, 12.292/2010 (BRASIL, 2010h), que autoriza o Poder Executivo a realizar doação para a reconstrução de Gaza.

A lei 10.643/2003 (BRASIL, 2003c) autoriza o Poder Executivo a doar à República do Paraguai vacinas e 
equipamentos para o combate da febre aftosa, em um gesto que visa proteger a importação da mesma e também evitar transmissão para o rebanho brasileiro, que impossibilitaria a sua comercialização. Ainda à República do Paraguai, a lei 11.444/2007 dispõe sobre a doação financeira cujo objetivo é de

[...] fomentar ações naquele País para a modernização da administração tributária e aduaneira e a redução de desequilíbrios locais, principalmente nas áreas sociais e econômicas, buscando melhor integração entre os países membros do Mercado Comum do Sul - MERCOSUL (BRASIL, 2007d).

Outras doações foram autorizadas pela lei 11.881/2008, que autoriza o Poder Executivo a doar estoques públicos de alimentos à República de Cuba, do Haiti, de Honduras e à Jamaica (BRASIL, 2008d).

A categoria mais numerosa dentro da Geopolítica, “Organizações Internacionais", prevê a contribuição financeira do Brasil a organismos internacionais, como a Organização Mundial de Turismo, ao Grupo de Países em Desenvolvimento (G24) e ao sistema das Nações Unidas, por exemplo. De acordo com o Ministério do Planejamento ${ }^{8}$, tais contribuições, obrigatórias ou voluntárias, acontecem porque:

Uma vez que o Brasil escolhe se tornar membro de um Organismo, pode passar a ter a obrigação de contribuir para a sua manutenção. Caso não ocorra o pagamento, o país pode perder o seu direito a voto em importantes discussões e decisões, que podem gerar impactos diretos ao país (BRASIL, 2015b).

Tais proposições estão espalhadas em diversas leis, mas os dados existentes não revelam a real importância dos organismos internacionais dentro da Política Externa feita pelo governo brasileiro, pois parte das contribuições estão classificadas como "Contribuição a Outros Organismos Internacionais" e portanto pode representar um número muito maior de participações. Mesmo assim, ainda é possível verificar uma predominância das proposições das organizações internacionais dentro da agenda presidencial, refletindo uma atitude multilateralista e equilibrada das relações internacionais brasileiras, procurando visibilizar o país no cenário internacional, no que Almeida (2003, 2004) se refere como uma política externa engajada. Segue o resumo dos dados no Gráfico 4:

\footnotetext{
${ }^{8}$ Retirado do site do Ministério do Planejamento, no endereço: http:/www.planejamento.gov.br/servicos/faq/assuntos-internacionais/ contribuicao-a-organismos-internacionais (BRASIL, 2015b).
}

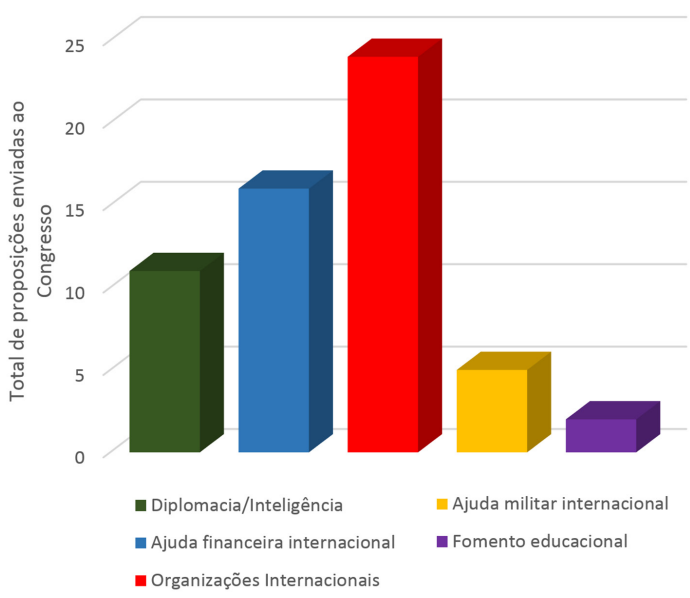

Gráfico 4. Proposições de Geopolítica enviadas ao Congresso.

\section{Considerações finais}

O objetivo deste trabalho foi procurar entender qual é o papel dos partidos políticos em política externa, levando o argumento à atuação do Presidente e a formação de sua agenda no Congresso. Tomou-se como pressuposto o fato de que o Presidente do Executivo é um representante do seu partido quando está no poder, e como se dá a sua produção de legislação, como pontuado por Aleman e Navia (2009), Peake (2001), e Edwards III e Wood (1999).

Dentro das possibilidades de ação de um partido político em política externa, Oliveira e Onuki (2010) indicam que esses podem ser responsáveis pela formação, agregação/manutenção e impacto de suas preferências no campo. De maneira geral, os estudos feitos sobre essa atuação versam sobre temas que envolvem economia, como apontado anteriormente nesse texto e envolvem a discussão de parcerias estratégicas e integração regional, tendendo à possuírem programas de governo genéricos para a área. Outrossim, os partidos podem participar da política externa de um país através da competição partidária que, como mostra Winslett (2012), serve como impulsionador de política externa ao comprometer a posição de poder interna do partido no poder e incentivar que o partido adote políticas externas mais radicais, seguindo a lógica de jogos de dois níveis de Putnam (1988).

Qualitativamente, os dados confirmam os achados de Diniz (2013), mostrando uma aproximação da administração de Lula para com países africanos. A autora analisa acordos internacionais bilaterais feitos com países e essa mesma tendência se verifica na agenda presidencial no Congresso. Além disso, há de se destacar a centralidade dos organismos internacionais nas leis ordinárias que tiveram origem 
no Poder Executivo. Para Keohane et al. (2009), a participação em instituições multilaterais pode melhorar a qualidade da democracia de um país, muitas vezes ajudando instituições a restringirem o poder de setores de interesse, protegendo direitos individuais, e melhorando a qualidade da deliberação democrática, também aumentando as capacidades para atingir fins públicos importantes.

Tal interdependência econômica e ganhos absolutos refletem uma preocupação explicada pela teoria neoinstitucionalista das relações internacionais (DIMAGGI; POWELL, 1991). Além disso, a teoria também ajuda a explicar a razão pela qual o Brasil ajudou tantos países durante o governo Lula, uma vez que o interesse central dos atores é cooperar interestatalmente para a resolução de problemas. Dentro da teoria idealista das relações internacionais (JACKSON; SORENSEN, 2007), que possui como um de seus conceitos centrais a segurança coletiva dos países, explica-se a presença da ajuda militar internacional, fruto da preocupação brasileira para com a segurança regional.

\section{Referências}

ALDRICH, J. Why parties? The origin and transformation of political parties in America. Chicago: The University of Chicago Press, 1985.

ALDRICH, J. et al. Foreign policy and the electoral connection. Annual Review of Political Science, v. 9, p. 477-502, 2006.

ALEMÁN, E.; NAVIA, P. Institutions and the legislative success of 'strong' presidents: an analysis of government bills in chile. The Journal of Legislative Studies, v. 15, n. 4, 2009.

ALMEIDA, C. Sistema de Vigilância da Amazônia SIVAM, perspectivas da economia de defesa. Revista $A D N$, v. 793, p. 42-57, 2002.

ALMEIDA, P. A política internacional do partido dos trabalhadores: da fundação à diplomacia do governo Lula. Revista de Sociologia e Politica, v. 20, p. 87102, 2003.

ALMEIDA, P. Uma política externa engajada: a diplomacia do governo Lula. Revista Brasileira de Politica Internacional, v. 47, n. 1, p. 162-184, 2004.

BAUMGARTNER, F. R.; JONES, B. D. Agendas and instability in american politics. Chicago: University of Chicago Press, 1993.

BRASIL. Lei $\mathrm{n}^{\circ} 10.818$, de 16 de dezembro de 2003. Diário Oficial [da] República Federativa do Brasil, Brasília, DF, 17 dez. 2003a. Seção 1, p. 17.

BRASIL. Lei no 10685 de 02 de março de 2003. Diário Oficial [da] República Federativa do Brasil, Brasília, DF, 02 mar. 2003b.
BRASIL. Lei n ${ }^{\circ} 10.643$ de 14 de março de 2003. Diário Oficial [da] República Federativa do Brasil, Brasília, DF, 15 mar. 2003c. Seção 1, p. 3513.

BRASIL. Lei n ${ }^{\circ} 11.007$, de 16 de dezembro de 2004. Diário Oficial [da] República Federativa do Brasil, Brasília, DF, 17 dez. 2004a. Seção 1, p. 7.

BRASIL. Lei n ${ }^{\circ} 11.085$, de 31 de dezembro de 2004. Diário Oficial [da] República Federativa do Brasil, Brasília, DF, 31 dez. 2004b.

BRASIL. Lei n ${ }^{\circ} 11.081$, de 31 de dezembro de 2004. Diário Oficial [da] República Federativa do Brasil, Brasília, DF, 31 dez. 2004c.

BRASIL. Lei n ${ }^{\circ}$ 11.071, de 30 de dezembro de 2004. Diário Oficial [da] República Federativa do Brasil, Brasília, DF, 31 dez. 2004d.

BRASIL. Lei n ${ }^{\circ} 11.066$, de 30 de dezembro de 2004. Diário Oficial [da] República Federativa do Brasil, Brasília, DF, 30 dez. 2004e.

BRASIL. Lei n ${ }^{\circ} 10.893$ de 13 de julho de 2004. Diário Oficial [da] República Federativa do Brasil, Brasília, DF, 14 jul. $2004 f$.

BRASIL. Lei n ${ }^{\circ} 11.033$ de 21 de dezembro de 2004. Diário Oficial [da] República Federativa do Brasil, Brasília, DF, 22 dez. 2004g.

BRASIL. Lei n ${ }^{\circ} 10.938$, de 12 de agosto de 2004. Diário Oficial [da] República Federativa do Brasil, Brasília, DF, 13 ago. 2004h. Seção 1, p. 11

BRASIL. Lei no 11.199, de 24 de novembro de 2005. Diário Oficial [da] República Federativa do Brasil, Brasília, DF, 25 nov. 2005a. p. 3.

BRASIL. Lei n ${ }^{\circ} 11.224$, de 21 de dezembro de 2005. Diário Oficial [da] República Federativa do Brasil, Brasília, DF, 21 dez. 2005b. p. 51.

BRASIL. Lei n ${ }^{\circ} 11.253$, de 27 de dezembro de 2005. Diário Oficial [da] República Federativa do Brasil, Brasília, DF, 28 dez. 2005c.

BRASIL. Lei ${ }^{\circ} 11.225$, de 22 de dezembro de 2005. Diário Oficial [da] República Federativa do Brasil, Brasília, DF, 22 dez. 2005d.

BRASIL. Lei $\mathrm{n}^{\circ}$ 11.206, de 15 de dezembro de 2005. Diário Oficial [da] República Federativa do Brasil, Brasília, DF, 16 dez. 2005e. Seção 1, p. 2.

BRASIL. Lei $\mathrm{n}^{\circ}$ 11.230, de 22 de dezembro de 2005. Diário Oficial [da] República Federativa do Brasil, Brasília, DF, 22 dez. 2005f. Seção 1, p. 35

BRASIL. Lei $n^{\circ} 11.130$, de $1^{\circ}$ de julho de 2005. Diário Oficial [da] República Federativa do Brasil, Brasília, DF, 04 jul. $2005 \mathrm{~g}$.

BRASIL. Lei n ${ }^{\circ} 11.537$, de 6 de novembro de 2007. Diário Oficial [da] República Federativa do Brasil, Brasília, DF, 07 nov. 2007a.

BRASIL. Lei n ${ }^{\circ} 11.517$ de 28 de agosto de 2007. Diário Oficial [da] República Federativa do Brasil, Brasília, DF, 28 ago. $2007 b$.

BRASIL. Lei n ${ }^{\circ} 11.537$, de 6 de novembro de 2007. Diário Oficial [da] República Federativa do Brasil, Brasília, DF, 07 nov. 2007c. Seção 1, p. 1. 
BRASIL. Lei n ${ }^{\circ} 11.444$ de 05 de Janeiro de 2007. Diário Oficial [da] República Federativa do Brasil, Brasília, DF, 08 jan. $2007 \mathrm{~d}$.

BRASIL. Lei $\mathrm{n}^{\circ} 11.824$, de 13 de novembro de 2008. Diário Oficial [da] República Federativa do Brasil, Brasília, DF, 14 nov. 2008a.

BRASIL. Lei n ${ }^{\circ} 11.814$, de 13 de novembro de 2008 . Diário Oficial [da] República Federativa do Brasil, Brasília, DF, 14 nov. 2008b. Seção 1, p. 13

BRASIL. Lei ${ }^{\circ} 11.852$, de 3 de dezembro de 2008. Diário Oficial [da] República Federativa do Brasil, Brasília, DF, 04 dez. 2008c. Seção 1, p. 32.

BRASIL. Lei n ${ }^{\circ} 11.881$, de 23 de Dezembro de 2008. Diário Oficial [da] República Federativa do Brasil, Brasília, DF, 24 dez. 2008d. Seção 1, p. 1.

BRASIL. Lei no 12.009, de 29 de julho de 2009. Diário Oficial [da] República Federativa do Brasil, Brasília, DF, 30 jul. 2009a.

BRASIL. Lei no 11.957, de 25 de junho de 2009. Diário Oficial [da] República Federativa do Brasil, Brasília, DF, 26 jun. 2009b.

BRASIL. Lei $\mathrm{n}^{\circ} 12.163$, de 29 de dezembro de 2009. Diário Oficial [da] República Federativa do Brasil, Brasília, DF, 29 dez. 2009c. Seção 1, p. 14.

BRASIL. Lei no 11.953, de 25 de junho de 2009. Diário Oficial [da] República Federativa do Brasil, Brasília, DF, 26 jun. 2009d.

BRASIL. Lei $\mathrm{n}^{\circ}$ 12.373, de 30 de dezembro de 2010 . Diário Oficial [da] República Federativa do Brasil, Brasília, DF, 30 dez. 2010a.

BRASIL. Lei ${ }^{\circ} 12.271$, de 24 de junho de 2010. Diário Oficial [da] República Federativa do Brasil, Brasília, DF, 25 jun. 2010b.

BRASIL. Lei n ${ }^{\circ} 12.257$ de 15 de junho de 2010. Diário Oficial [da] República Federativa do Brasil, Brasília, DF, 16 jun. 2010c. Seção 1, p. 4.

BRASIL. Lei n ${ }^{\circ} 12.189$ de 12 de janeiro de 2010. Diário Oficial [da] República Federativa do Brasil, Brasília, DF, 13 jan. 2010d. Seção 1, p. 1.

BRASIL. Lei n ${ }^{\circ} 12.289$ de 20 de julho de 2010. Diário Oficial [da] República Federativa do Brasil, Brasília, DF, 27 jul. 2010e. Seção 1, p. 4

BRASIL. Lei $\mathrm{n}^{\circ}$ 12.337, de 12 de novembro de 2010. Diário Oficial [da] República Federativa do Brasil, Brasília, DF, 29 dez. $2010 f$.

BRASIL. Lei $\mathrm{n}^{\circ} 12.231$, de 22 de abril de 2010. Diário Oficial [da] República Federativa do Brasil, Brasília, DF, 23 abr. 2010g. Seção 1, p. 1.

BRASIL. Lei n ${ }^{\circ} 12.292$, de 20 de julho de 2010. Diário Oficial [da] República Federativa do Brasil, Brasília, DF, 21 jul. 2010h.

BRASIL. Lei n ${ }^{\circ} 12.195$, de 18 de dezembro de 2013. Diário Oficial [da] República Federativa do Brasil, Brasília, DF, 19 dez. 2013.

BRASIL. Portal da legislação. Brasília: Governo Federal, 2015a. Disponível em: <http://www4.planalto.gov.br/ legislacao>. Acesso em: 01 nov. 2015.
BRASIL. Ministério do Planejamento, Orçamento e Gestão. Contribuição a organismos internacionais. Brasília: Governo Federal, 2015b. Disponível em: $<$ http://www.planejamento.gov.br/servicos/faq/ assuntos-internacionais/contribuicao-a-organismosinternacionais>. Acesso em: 01 nov. 2015

CARR, E. H. Nationalism and after. New York: Macmillan, 1945.

CELlARD, A. A análise documental. In: PIRES, A. P. et al. (Orgs.). A pesquisa qualitativa. Petrópolis: Editora Vozes, 2008. p. 295-316.

DEUTSCH, K. On the concepts of politics and power. In: FARREL, J.; SMITH, A. (Eds.). Theory and reality in international relations. New York: Columbia University Press, 1967. p. 52-54.

DIMAGGIO, P.; POWELL, W. Introduction. In: POWELL, W.; DIMAGGIO, P. (Eds.). The new institutionalism in organizational analysis. Chicago: University of Chicago Press, 1991. p. 1-38.

DINIZ, S. Acordos internacionais de cooperação nos governos Fernando Henrique e Lula. E-Legis, v. 10, p. 26-41, 2013.

DINIZ, S.; RIBEIRO, C. The role of the brazilian congress in foreign policy: an empirical contribution to the debate. Brazilian Political Science Review, v. 2, n. 2, p. 10-38, 2008.

DINIZ, S.; RIBEIRO, C. Acordos internacionais e controle parlamentar no Brasil. Revista de Sociologia e Politica, v. 18, n. 37, p. 75-79, 2010.

DUVERGER, M. Political parties: their organization and activity in the modern state. New York: Wiley, 1954.

DUVERGER, M. Os partidos politicos. Rio de Janeiro: Zahar, 1970.

EDWARDS III, G.; WOOD, B. D. Who influences whom? the president, congress, and the media. The American Political Science Review, v. 93, n. 2, 1999.

ELDERSVELD, S. Political parties in american society. New York: Basic Books, 1982.

HAGAN, J. Political opposition and foreign policy in comparative perspective. Boulder: Lynne Rienner, 1993.

HAGAN, J. Domestic political explanations in the analysis of foreign policy. In: NEACK, L.; HEY, J.; HANEY, P. (Eds.). Foreign policy analysis: continuity and change in its second generation. Upper Saddle River: Prentice Hall, 1995. p. 117-138.

HEBLING, M. A formação da agenda presidencial de política externa no congresso durante o governo Dilma. In: SEMANA DE PÓS-GRADUAÇÃO EM CIÊNCIAS SOCIAIS, 13., 2014, Araraquara. Anais... Araraquara: UNESP, 2014.

HERMANN, C.; HERMANN, M. Who makes foreign policy decisions and how: an empirical inquiry. International Studies Quarterly, v. 33, n. 4, p. 361387, 1989.

HOLSTI, O. Public opinion and foreign policy: challenges to the almond-lippmann consensus mershon. International Studies Quarterly, v. 36, n. 4, p. 439-466, 1992. 
HOWARD, M. War and the liberal conscience. Oxford: Rutgers University Press, 1978.

JACKSON, R.; SØRENSEN, G. Introdução às relações internacionais: teorias e abordagens. Rio de Janeiro: Jorge Zahar, 2007.

KATZNELSON, I.; LAPINSKI, J. The substance of representation: studying political content and legislative behavior. In: ADLER, S.; LAPINSKI, J. (Eds.). The macropolitics of congress. Princeton: Princeton University Press, 2006. p. 96-126.

KEOHANE, R.; MACEDO, S.; MORAVCSKI, A. Democracy-enhancing multilateralism. International Organization, n. 63, p. 1-31, 2009.

KEOHANE, R.; NYE, J. Power and interdependence: world politics in transition. Boston: Little, 1977.

KINGDON, J. Agendas, alternatives, and public policies. New York: Harper Collins, 2003.

KIRCHHEIMER, O. The transformation of the western european party systems. In: LAPALOMBARA, J.; WEINER, M. (Eds.). Political parties and political development. Princenton: PUP, 1966. p. 177-200.

KLEISTRA, Y.; MAYER, I. Stability and flux in foreign affairs: modelling policy and organizational change. Cooperation and Conflict, v. 36, p. 381-414, 2001.

LENTNER, H. Public policy and foreign policy: divergences, intersections, exchange. Review of Policy Research, v. 23, n. 1, p. 169-181, 2006.

LIMA, M. A política externa brasileira e os desafios da cooperação sul-sul. Revista Brasileira de Política Internacional, v. 48, n. 1, p. 24-59, 2005.

LIPSET, S. Reflections on capitalism, socialism and democracy. Journal of Democracy, v. 4, n. 2, p. 43$55,1993$.

LIPSET, S.; ROKKAN, S. Cleavage structures, party systems and voter alignments. In: LIPSET, S. M.; ROKKAN, S. (Eds.). Party systems and voter alignments: cross national perspectives. New York: Free Press, 1967. p. 91-138.

LOWI, T. American business, public policy, case-studies, and political theory. World Politics, v. 16, p. 677$715,1964$.

LOWI, T. Decision making vs policy making: toward an antidote for technocracy. Public Administration Review, v. 30, p. 314-25, 1970.

MAIR, P. Party system change: approaches and interpretations. Oxford: Clarendon Press, 1997.

MARTIN, L. Democratic commitments: legislatures and international cooperation. Princeton: Princeton University Press, 2000.

MILANI, C.; PINHEIRO, L. Política externa brasileira: os desafios de sua caracterização como política pública. Contexto Internacional, v. 35, n. 1, p. 11-41, 2013.
MILNER, H. Interests, institutions and information: domestic politics and international relations. New Jersey: Princeton University Press, 1997.

MITRANY, D. The functional approach to world organisation. International Affairs, v. 24, n. 3, p. 350-363, 1948.

NYE, J. S. Neorealism and neoliberalismo. World Politics, v. 40, n. 2, p. 235-251, 1988.

OLIVEIRA, A.; ONUKI, J. Eleições, partidos políticos e política externa no Brasil. Revista Política Hoje, v. 19, n. 1, p. 144-185, 2010.

PANEBIANCO, A. Modelos de partidos: organização e poder nos partidos políticos. São Paulo: Martins Fontes, 2005.

PEAKE, J. Agenda setting in foreign policy. Political Research Quarterly, v. 54, n. 1, p.69-86, 2001.

PIERANTI, O.; SILVA, L. A questão amazônica e a política de defesa nacional. Cadernos Ebape, v. 5, n. 1, p. 1-11, 2007.

PIERSON, P. Politics in Time: history, institutions and social analysis. Princeton: Princeton University Press, 2004.

POWELL, R. Anarchy in international relations theory: the neo-realist-neoliberal debate. International Organization, v. 48, n. 2, p. 313-344, 1994.

PUTNAM, R. Diplomacy and domestic politics: the logic of two-level games. International Organization, v. 42, n. 3, p. 427-460, 1988.

RISE-KAPPEN, T. Public opinion, domestic structure, and foreign policy in liberal democracies. World Politics, v. 43, n. 4, p. 479-512, 1991.

ROGOSWKI, R. Institutions as constraints on strategic choice. In: LAKE, D. A.; POWELL, R. (Eds.). Strategic choice and international relations, 1999. p. 115-136.

THELEN, K. Historical institutionalism in comparative politics. Annual Review of Political Science, v. 2, p. 369-404, 1999.

UNIVERSIDADE DA INTEGRAÇÃO INTERNACIONAL DA LUSOFONIAAFRO-BRASILEIRA - UNILAB. Integração Internacional. 2015. Disponível em: <http:// www.unilab.edu.br/nosso-diferencial-de-integracaointernacional>. Acesso em: 01 jan. 2015.

WINSLETT, G. Party competition as a driver of foreign policy: explaining changes in the British labour party's immigration polices and the Turkish akp's approach to cyprus. The Josef Korbel Journal of Advanced International Studies, v. 4, p. 127-153, 2012.

YOUNG, O. R. International cooperation: building regimes for natural resources and the environment. Ithaca: Cornell University Press, 1982.

Recebido: 20 jun., 2015 Aceito: 05 nov., 2015 